\title{
INVESTIGATION OF TURBULENT TIP LEAKAGE VORTEX IN AN AXIAL WATER JET PUMP WITH LARGE EDDY SIMULATION
}

\author{
Chunill Hah ${ }^{1}$, Joseph Katz ${ }^{2}$ \\ 1NASA Glenn Research Center \\ Cleveland, Ohio USA \\ 2Dept. of Mechanical Engineering \\ Johns Hopkins University
}

\begin{abstract}
Detailed steady and unsteady numerical studies were performed to investigate tip clearance flow in an axial water jet pump. The primary objective is to understand physics of unsteady tip clearance flow, unsteady tip leakage vortex, and cavitation inception in an axial water jet pump. Steady pressure field and resulting steady tip leakage vortex from a steady flow analysis do not seem to explain measured cavitation inception correctly. The measured flow field near the tip is unsteady and measured cavitation inception is highly transient. Flow visualization with cavitation bubbles shows that the leakage vortex is oscillating significantly and many intermittent vortex ropes are present between the suction side of the blade and the tip leakage core vortex. Although the flow field is highly transient, the overall flow structure is stable and a characteristic frequency seems to exist. To capture relevant flow physics as much as possible, a Reynolds-averaged Navier-Stokes (RANS) calculation and a Large Eddy Simulation (LES) were applied for the current investigation. The present study reveals that several vortices from the tip leakage vortex system cross the tip gap of the adjacent blade periodically. Sudden changes in local pressure field inside tip gap due to these vortices create vortex ropes. The instantaneous pressure filed inside the tip gap is drastically different from that of the steady flow simulation. Unsteady flow simulation which can calculate unsteady vortex motion is necessary to calculate cavitation inception accurately even at design flow condition in such a water jet pump.
\end{abstract}

\section{INTRODUCTION}

Water jet propulsion with axial pump is increasingly applied for various surface ships. Water jet propulsion has several advantages compared to the conventional propulsion including maneuverability and high-speed capability.
Advanced design tools based on Computational Fluid Dynamics have been widely applied in developing latest generation of axial pumps for the water jet propulsion (Brewton et al. [2006], Michael et al [2008]).

It is well known that cavitation on marine propellers/pumps is a source of noise, hull vibration, and erosion of materials. Therefore, prediction and prevention of cavitation are of great interest. Also, it is widely observed that cavitation inception occurs typically in the tip leakage vortex region before it occurs on the blade surface. However, detailed mechanism of cavitation inception in the tip leakage vortex is not well understood and data from model testing are still heavily used during the design phase.

Recent experimental study on tip leakage flow in an axial pump of a water jet by Miorini et al [2009] showed that the tip leakage flow is highly transient and cavitation inception process can not be calculated adequately with the steady Reynolds-averaged Navier-Stokes simulations.

Tip clearance flow in turbomachinery has been studied widely both experimentally and analytically for many years. Although non-intrusive measurement technique has been advanced significantly, detailed measurements of steady and unsteady flow structures near the tip clearance region in turbomachinery remain as one of great challenges for the experimentalist. Many successful numerical studies on the tip leakage flow have been reported (for example, Hah [1986], Storer and Cumpsty [1991], Adamczyk et al. [1993], R.D. Moore [1982], and J. Denton [1993]). Most numerical studies on tip leakage flow in turbomachinery have been aimed to understand overall effects of tip leakage flow on the performance and applied steady flow analysis approach. Tip clearance flow is due to the pressure difference between the pressure side and the suction side of the blade in the tip gap. Tip leakage vortex is generated when the flow from tip gap interacts with the main flow. As the tip leakage vortex 
oscillates, unsteady pressure fields are induced and the flow field becomes quite complicated even at steady operation of the pump. Recently Miorini et al. [2009] applied a very advanced particle image velocimetry (PIV) to investigate detailed flow structure in a waterjet pump. The measured flow field showed many interesting flow features that could not be explained adequately with the conventional RANS simulations.

In the present study, a LES is applied to study unsteady flow physics in the tip region in addition to RANS. The primary objective is to explain details of steady and unsteady flow structures and resulting cavitation inception process in the present waterjet axial pump.

\section{TEST PUMP, TEST FACILITY, AND PIV SETUP}

Detailed flow field around a seven-bladed axial pump was investigated with various latest measurement techniques at a closed loop water tunnel at the Johns Hopkins University (see Wu et al. [2008]). The test pump is a scaled version of the ONR AxWJ-1. The original pump was designed by the Naval Surface Warfare Center Carderock Division for test and evaluation purpose. Details of the rotor design and measurement techniques are given by Miorini et al. [2009]. Fig. 1 shows test section of the single stage pump. The rotor diameter is $303.4 \mathrm{~mm}$ with the mean tip gap of 1 $\mathrm{mm}$. The rotor angular velocity is $900 \mathrm{rpm}$ and the Reynolds number based on the blade chord is $5.15 \times 10^{5}$. Figure 2 shows test pump and the casing. Flat external casing is used for PIV measurement. The blades and the casing are made of transparent acrylic. The pump is transparent and the reflective index of the working fluid matches that of the blade and casing. Therefore, PIV can be used to measure instantaneous flow field of the pump interior without any obstruction. Flow visualization was performed primarily with cavitaion. Details of the PIV setup and measurement procedures are given by Miorini et al. [2009].

\section{NUMERICAL PROCEDURE}

Both RANS and LES methods are applied in the present study. RANS was first applied to obtain overall flow structures at various operating conditions. RANS simulations were extensively applied in the design process of the current pump in addition to traditional design codes based on potential/Euler flow codes. As the flow fields from RANS simulation do not explain many measured flow features including cavitation inception, LES was applied to obtain detailed unsteady flow characteristics in the tip region., A standard two-equation turbulence model was used for the RANS. A Smagorinsky-type eddy-viscosity model was used for the subgrid stress tensor, and the standard dynamic model by Germano et al. [1991] was applied for the LES.

In the current study, the governing equations are solved with a pressure-based implicit method using a fully conservative control volume approach. A third-order accurate interpolation scheme is used for the discretization of convection terms and central differencing is used for the diffusion terms. The method is of second-order accuracy with smoothly varying grids. For the time-dependent terms, an implicit second-order scheme is used and a number of sub-iterations are performed at each time step. Details of the numerical method and applications to turbomachinery flows are given by Hah and Wennerstrom [1991] and Hah et al. [2005].

A computational grid with about $1,600,000$ nodes was used for the RANS simulation. The RANS grid consists of 200 nodes in streamwise direction, 100 nodes in blade-toblade direction, and 100 nodes in spanwise direction. 20 spanwise nodes are used to describe the tip gap and the tip clearance flow was calculated directly. For the LES simulation, the grid was further refined to $26,112,240$ nodes, with 198 nodes in the blade-to-blade direction, 157 nodes in the spanwise direction, and 840 nodes in the streamwise direction. The inflow boundary was located 2 average blade heights upstream of the rotor leading edge and the outflow boundary was located three blade heights from the trailing edge. The rotor tip clearance geometry is accurately represented by 44 nodes in the blade-to-blade direction, 47 nodes in the spanwise direction, and 600 nodes in the streamwise direction. I-grid topology is used to reduce grid skewness and a single-block grid is used. All the computations were performed with NASA's Columbia supercomputer system, which allows parallel computation with up to 512 processors.

Standard boundary conditions for an isolated rotor were applied at the boundaries of the computational domain. Circumferentially averaged static pressure at the casing was specified to control the mass flow rate. Non-reflecting boundary conditions were applied at the inlet and the exit boundaries. The present study is focused on the flow field when the pump is operating at near design condition. Therefore, only one blade passage was analyzed with the periodicity condition. Also upstream influence of the stator was not included and the isolated rotor flow field is simulated for the current study.

\section{TIP VORTEX AND PRESSURE FIELD}

Fig. 3 shows performance curve of the current pump at the nominal rotor speed. Current study investigates flow characteristics at the peak efficiency point marked in Figure 3. Initial development of the tip leakage vortex is shown in Figure 4 from the flow visualization with cavitation bubble. As the pressure at the center of tip leakage vortex is low, cavitation develops along the vortex core as shown in Figure 4. Figure 5 shows cavitation development above rotor tip and near suction side near the mid-chord. Figure 5 shows that low pressure spots exist above the rotor tip and several vortex ropes are formed between the blade suction side and the tip leakage vortex. Detailed examination of the flow visualization indicates that the formation of these vortex ropes is periodic and the locations oscillate as the pump operates. Although the formation of these vortex ropes is random, the process is stable and some characteristic frequency seems to exist. Figure 6 shows static pressure distributions at the rotor tip and at the middle of the tip gap from the RANS simulation. Results in Figure 6 show overall 
development and structure of the tip leakage vortex development clearly as flow visualization in Figure 4. However, no indication of local low pressure spots or development of vortex ropes can be found in the static pressure distribution from the RANS simulation. Instantaneous static pressure distributions and velocity vectors at the rotor tip from the LES are given in Figure 7. Instantaneous static pressure distribution at the middle of the tip gap from the LES simulation is given in Figure 8. The results Figures 7 and 8 clearly show low pressure spots above the tip and formation of the vortex ropes. Changes in static pressure distribution at the middle of the tip gap are given in Figure 9. Changes in the static pressure field shown in Figure 9 indicate that small vortices from the main tip leakage vortex cross over the tip gap. As these vortices move away from the suction side of the blade, interaction with the incoming main flow strengthen the vortices and vortex ropes are created. Like the flow visualization with cavitations bubble, the LES simulation shows the vortex ropes appear intermittently and oscillates with a certain frequency. Instantaneous pressure distribution at mid-span from the LES simulation is given in Figure 10. Instantaneous pressure distribution in Figure 10 clearly shows vortex shedding at the trailing edge. To investigate transient behavior of the vortex ropes, power spectrum of static pressure near the vortex rope marked as $\mathrm{A}$ in figure 7 and near the trailing edge at the mid-span, marked as $\mathrm{B}$, are examined further. FFT results of the static pressure at these two locations are given in Figure 11. Results in Figure 11 show that transient behavior of the vortex rope has the same characteristic frequency as the vortex shedding.

\section{COMPARISON OF TIP LEAKAGE CORE VORTEX DEVELOPMENT}

Like tip leakage vortex in compressors (see for example, Hah et al. [2008]), the tip leakage core vortex is formed by the fluid originating from the blade tip near the leading edge. Tip clearance flows originating from the blade tip section behind the leading edge area travel over the core vortex, some fluid strengthen the core vortex while other fluid near the casing forms another vortex when it meets the main passage flow. Figure 12 compares velocity vectors between measurement and the LES simulation at the meridional plane which is $56 \%$ of the axial chord from the leading edge. In Figure 12, the measured vectors represent only the meridional components from PIV measurement while the calculation shows all three velocity components at this plane. The comparison in Figure 12 shows fairly good agreement between the measured and calculated flow structure at this location. As seen in Figure 12, two distinctive vortices are formed at this meridional plane. For this pump, the tip leakage vortex travels toward the trailing edge of the adjacent blade and collapses when it meets adverse pressure gradient as shown by Miorini et al. [2009].

\section{CONCLUDING REMARKS}

Unsteady characteristics of the tip leakage vortex in the rotor of an axial water jet pump were investigated with RANS and LES simulations. Flow visualization with cavitation bubble indicates that pressure field near the tip leakage vortex is highly transient and local low pressure spots are formed inside the tip gap. Vortex ropes are formed intermittently between the blade suction side and the tip leakage core vortex. LES analysis indicates that vortices from the adjacent tip leakage vortex travel over the rotor tip and lower pressure spots are formed when these vortices interact with incoming main passage flow, resulting vortex ropes. The vortex ropes are formed intermittently and they have the same characteristic frequency as the vortex shedding at the trailing edge.

The present study shows that the tip leakage vortex induces very complicated transient flow field. To calculate cavitation inception in such a machine requires advanced unsteady flow simulation which can detect movement of dominant vortices and associated unsteady pressure field.

\section{ACKNOWLEDGMENTS}

The project has been sponsored by the Office of Naval Research under grant number N00014-06-0160 and N0001409-10867. The program Officer is Dr. Ki-Han Kim..

\section{REFERENCES}

Adamczyk, J. J., Celestina, M. L., and Greitzer, E. M.,1993, "The Role of Tip Clearance in High-Speed Fan Stall," ASME, Journal of Turbomachinery, Vol. 115, No. 1, pp. 28-39.

Brewton, S., Gowing, S., and Gorski, J., 2006,'Performance Predictions of a Waterjet Rotor and Rotor/Stator Combination using RANS Calculations," Proceedings of the $27^{\text {th }}$ Symposium on Naval Hydrodynamics, Rome Italy.

Denton, J. D., 1993, "Loss Mechanisms in Turbomachines," ASME Journal of Turbomachinery, Vol. 115, No. 4, pp. 621-656.

Germano, M., Piomelli, U., Moin, P., and Cabot, W. H., 1991, "A Dynamic Subgrid-Scale Eddy-Viscosity Model," Jouranl of Fluid Mechanics, Vol. A3, pp.1760176.

Hah, C., 1986, "A Numerical Modeling of Endwall and Tip-Clearance- Flow of an Isolated Compressor ," ASME Journal of Engineering for Gas Turbines and Power Vol. 108, No. 1, pp. 15-21.

Hah, C., Rabe, D. C., and Wadia, A.R., 2004, "Role of TipLeakage Vortices and Passage Shock in Stall Inception in a Swept Transonic Compressor Rotor," ASME Paper GT2004-53867.

Hah, C. and Wennerstrom, A. J., 1991, "ThreeDimensional Flow Fields Inside a Transonic Compressor with Swept Blades," ASME Journal of Turbomachinery, Vol. 113, No. 1, pp. 241-251. 
Michael, T., Scvhroeder, S., and Becnel, A., 2008," Design of the ONR AxWJ-2 Axial Flow Water Jet Pump," NSWCCD Department Report.

Miorini, R. L., Wu, H., Katz, J., 2009, "The Inner Structure and Evolution of a Turbulent Tip Leakage Vortex within an Axial Pump,"Part 1, Instantaneous Results - Part 2, Phase-Averaged Results, ASME Paper FEDSM200978534.

Moore, R. D., 1982, "Rotor Tip Clearance Effects on Overall and Blade-Element Performance of Axial-Flow Transonic Fan Stage,” NASA TP-2049.

Storer, J. A. and Cumpsty, N. A., 1991," Tip Leakage Flow in Axial Compressors," ASME Journal of Turbomachinery, Vol.113, pp. 252-259.

Wu, H., Soranna, F., Michael, T., Katz, J., and Jessup, S., 2008, "Cavitation in the Tip Region of the Rotor Blades within a Waterjet Pump," ASME Fluid Engineering Conference.

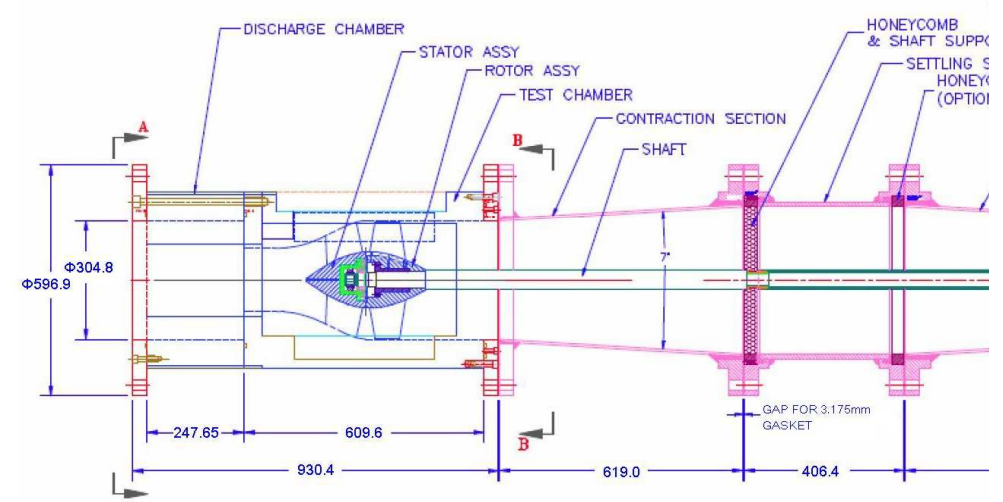

Figure 1: Test section of pump.

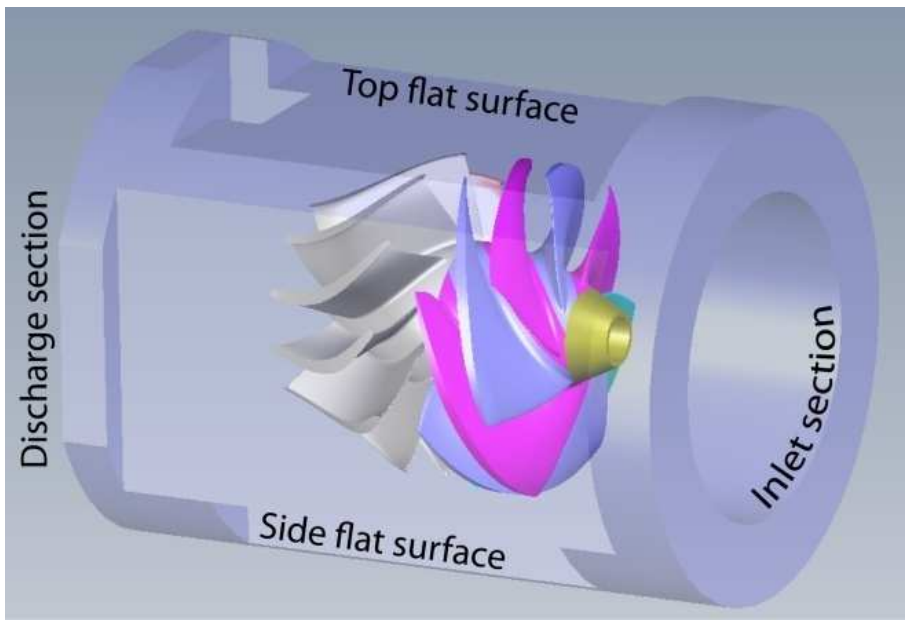

Figure 2: Test pump with casing.

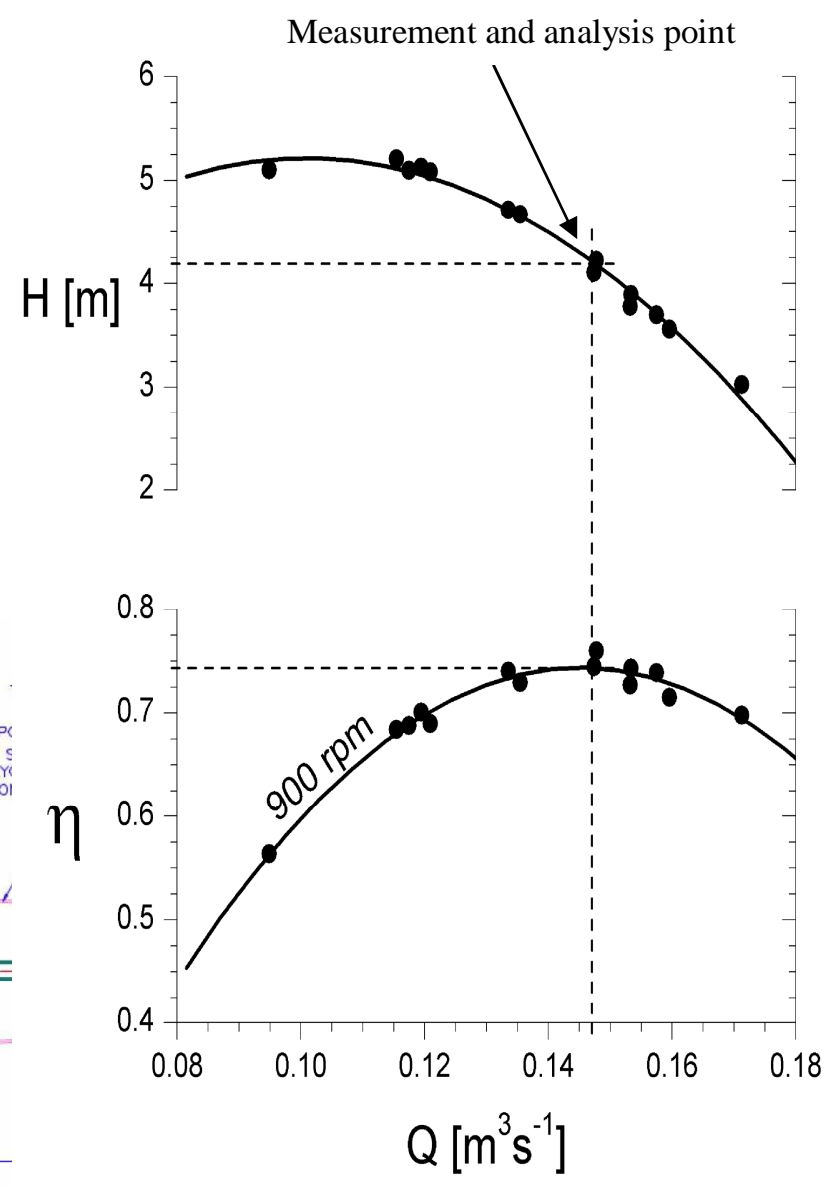

Figure 3: Pump performance curve. 

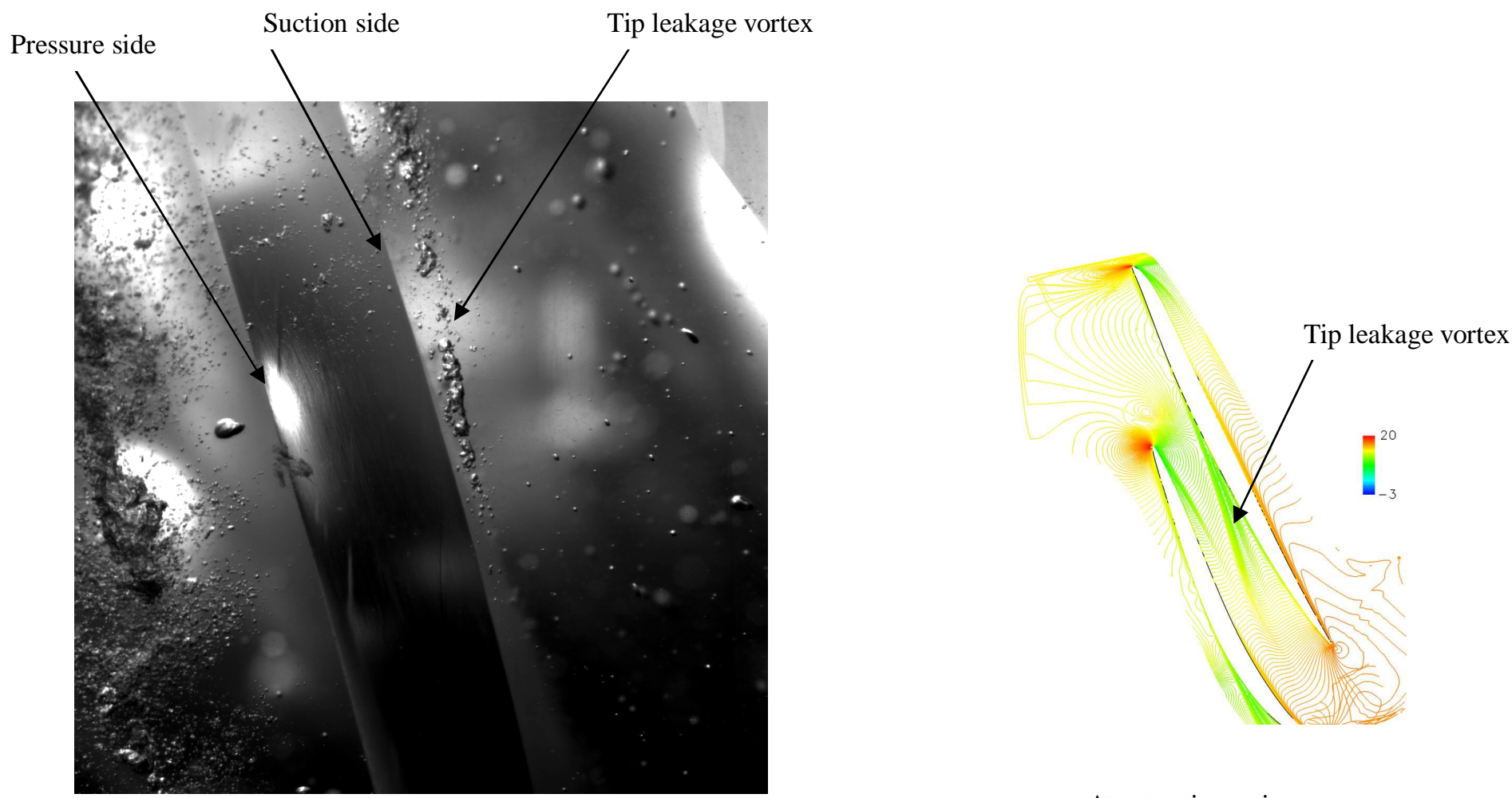

At rotor tip section

Figure 4: Tip leakage vortex development near suction side from flow visualization with cavitation.

Suction side
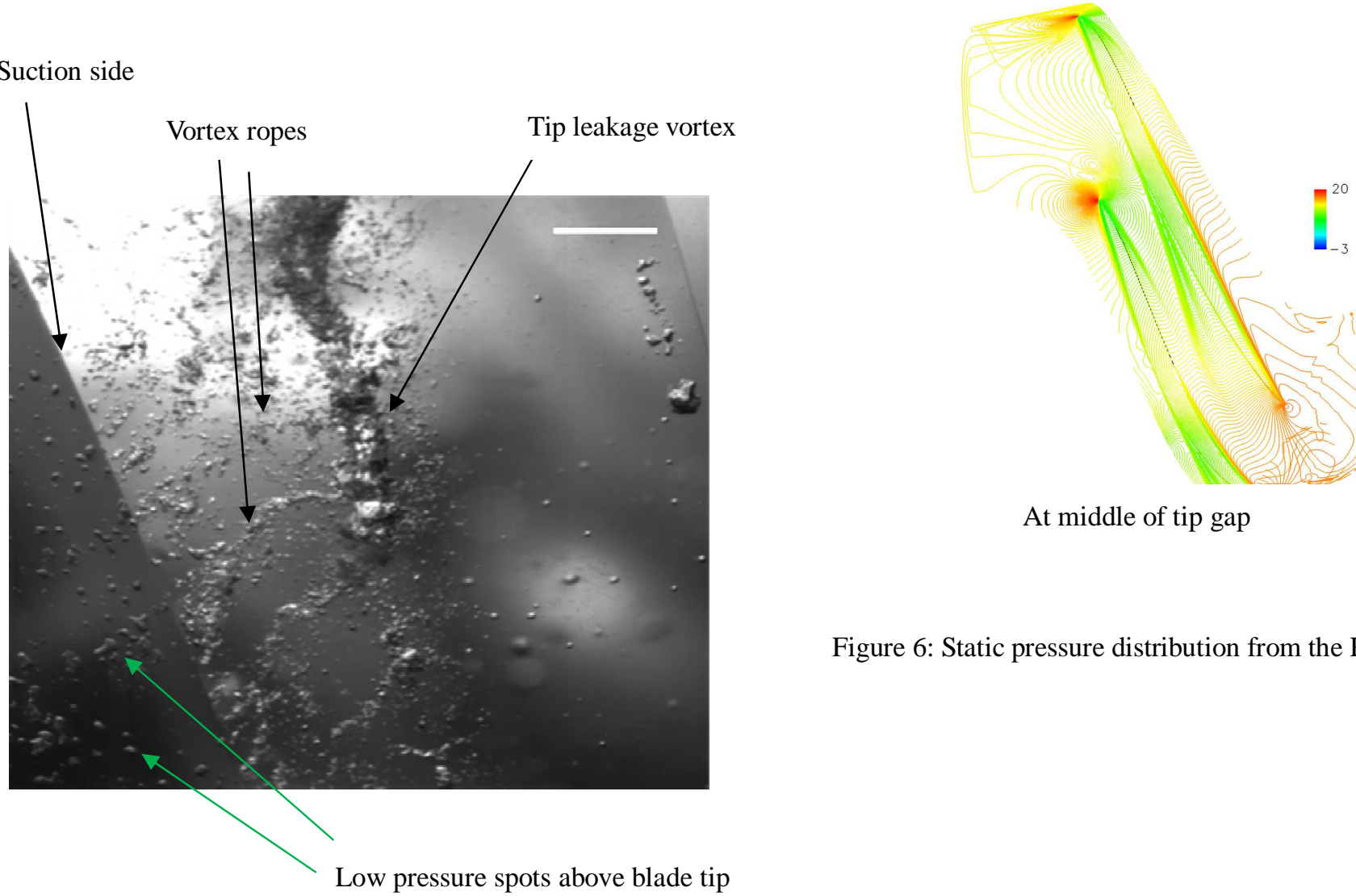

At middle of tip gap

Figure 6: Static pressure distribution from the RANS..

Figure 5: Low pressure spots and vortex rope development near suction surface. 
Tip leakage vortex
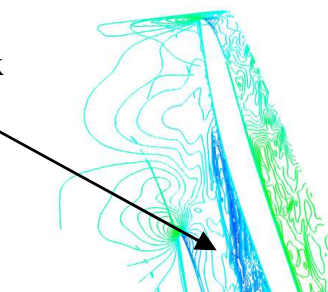

Vortex rope and point A for FFT

r

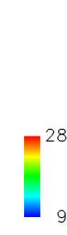

\section{1,}

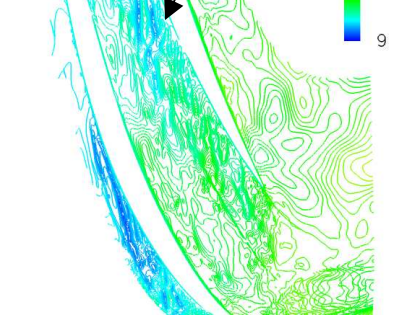

Instantaneous static pressure distribution, rotor tip

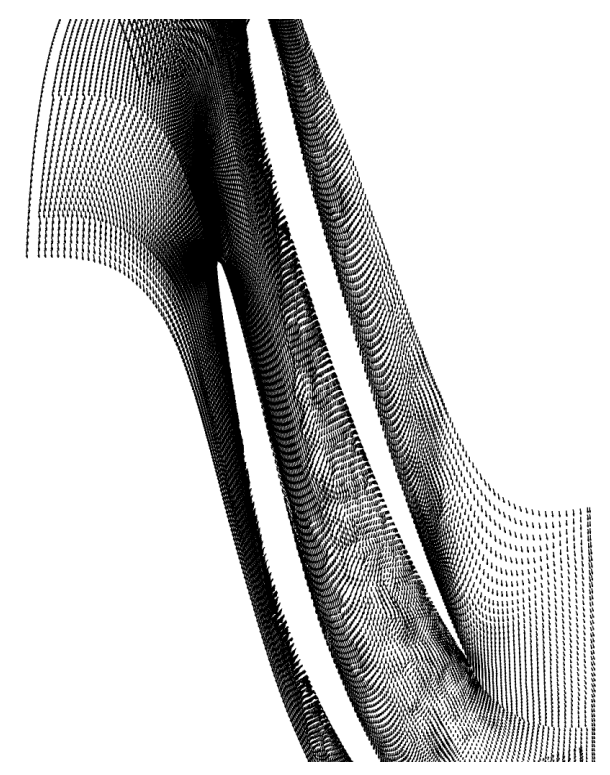

Instantaneous velocity vectors, rotor tip

Figure 7: Distribution of instantaneous static pressure and velocity vectors..

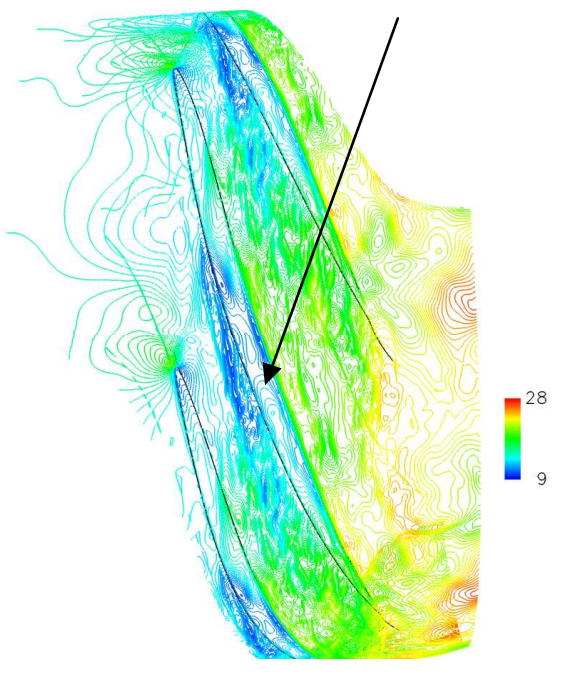

Figure 8: Instantaneous static pressure distribution at the middle of tip gap.

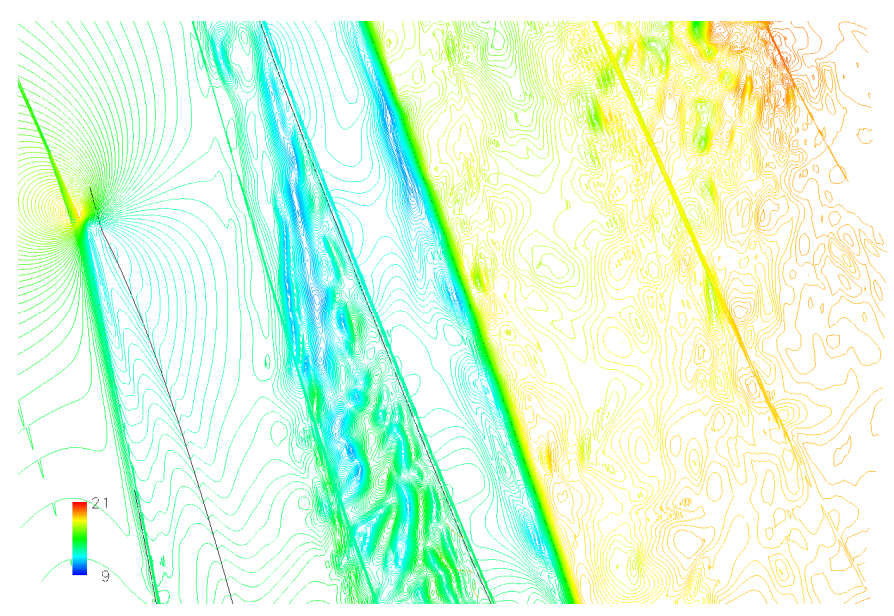

Time 1

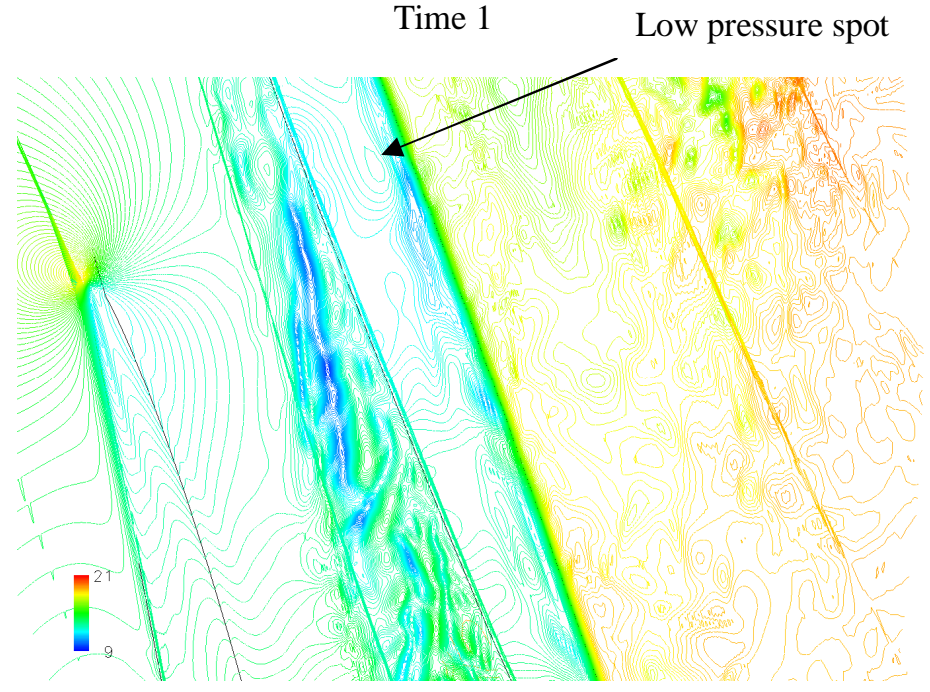

Time 2 


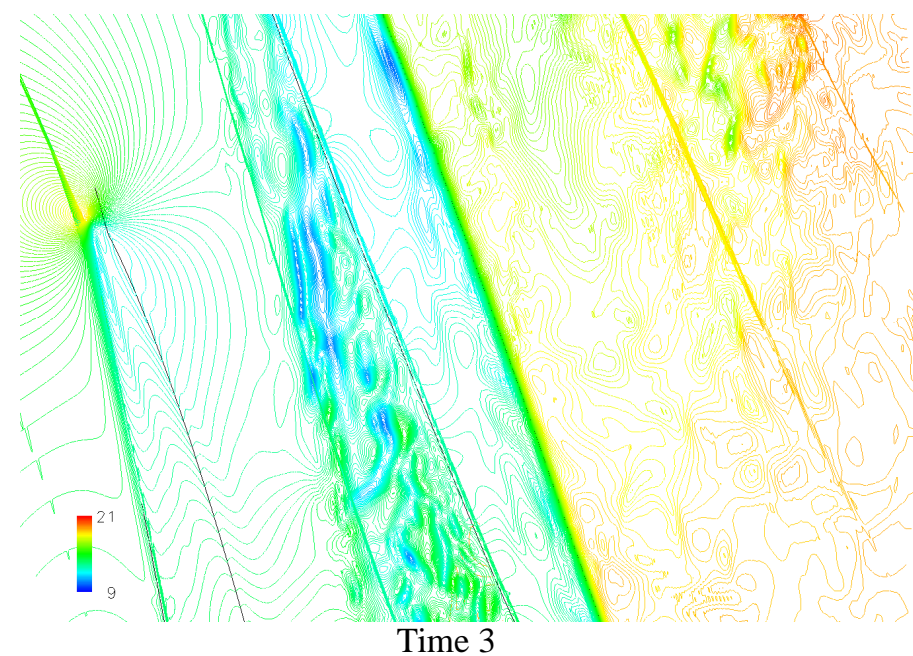

Figure 9: Changes in static pressure at the middle of tip gap at three equally spaced time steps.

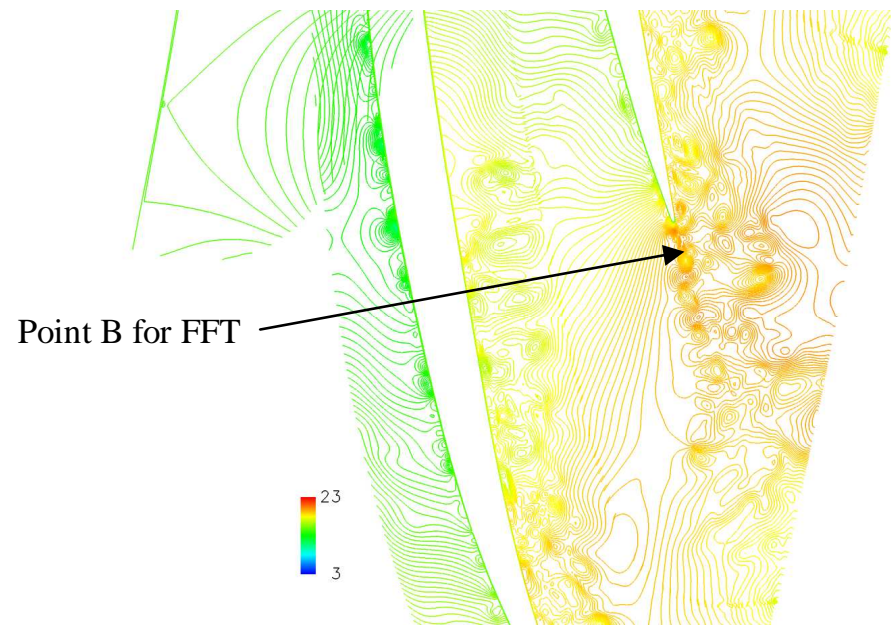

Figure 10: Instantaneous static pressure distribution at the mid-span.

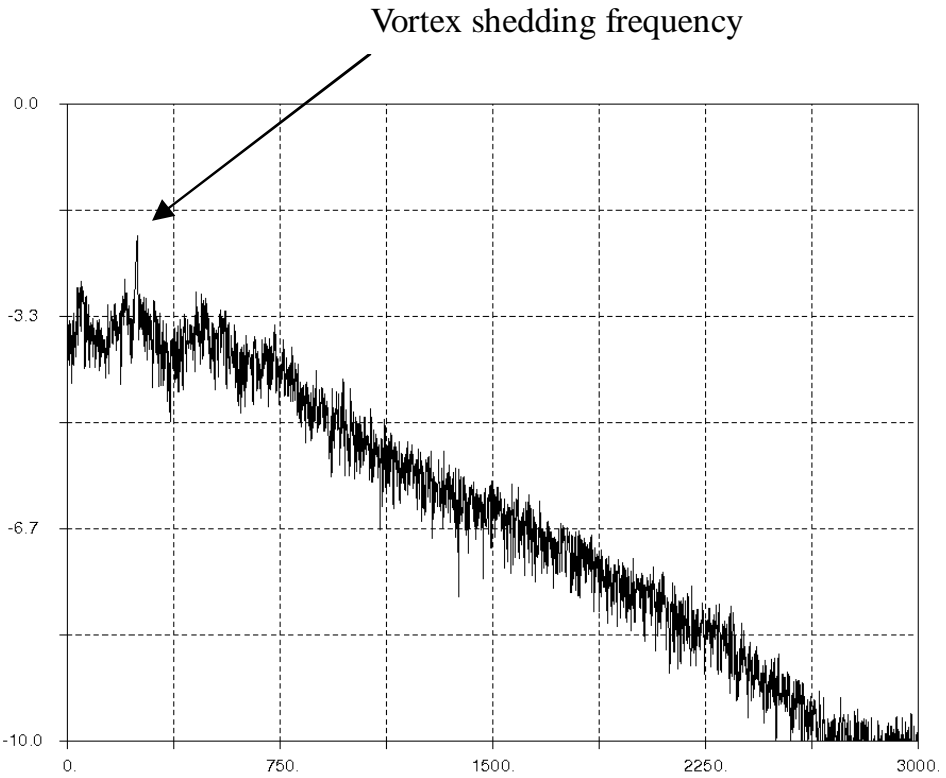

FFT of static pressure near trailing edge, mid-span, point B in Figure 10.

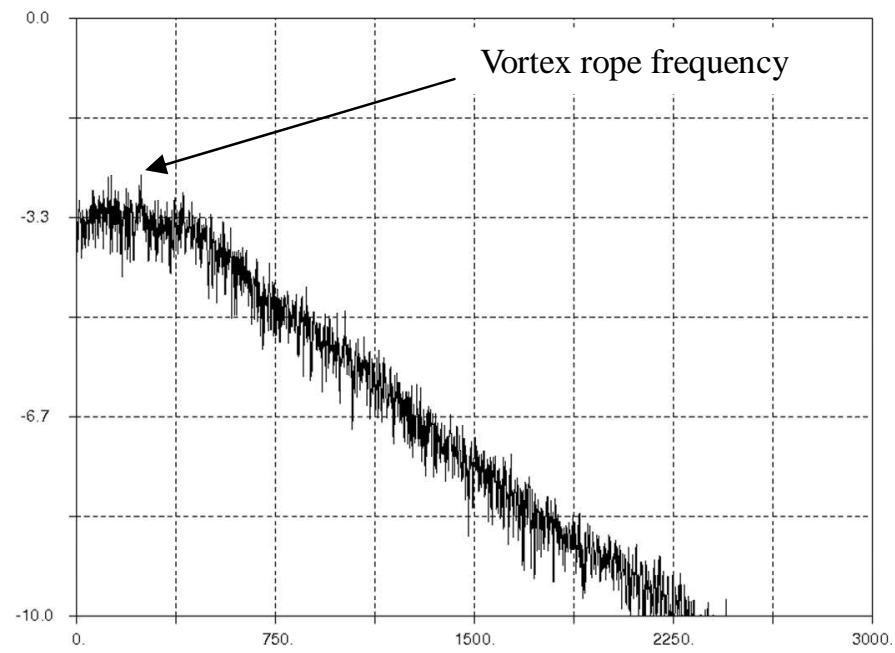

FFT of static pressure near suction surface, rotor tip, point A in Figure 7.

Figure 11: Power spectrums of static pressure at mid span and tip section. 


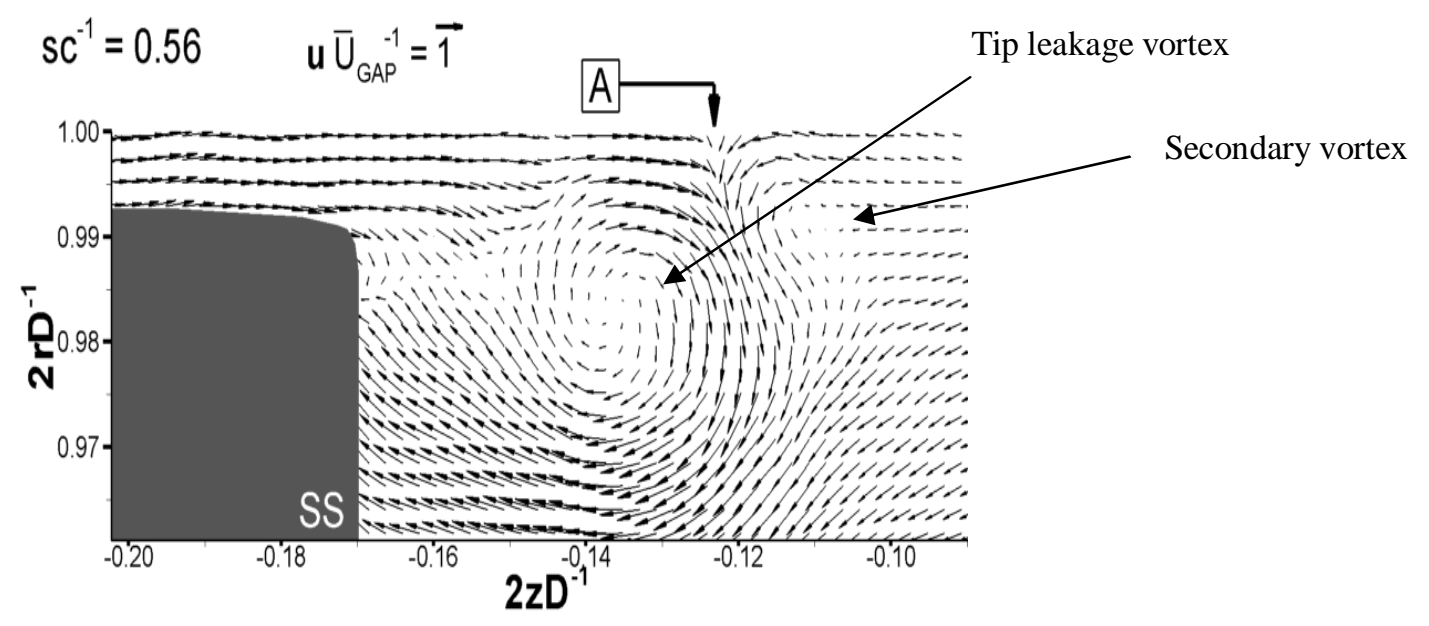

Measurement

Tip leakage vortex

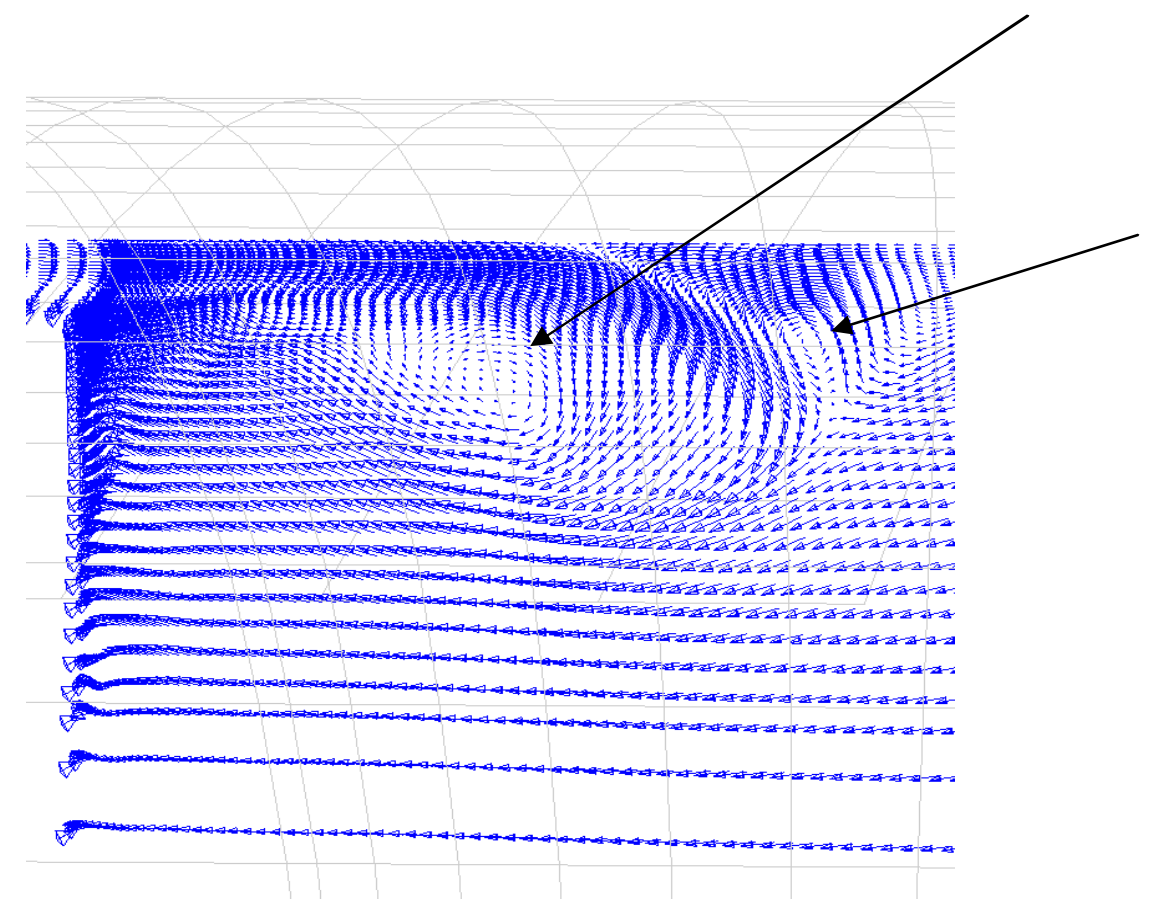

Secondary vortex

LES

Figure 12: Comparison of velocity distributions at the meridional plane of $56 \%$ axial chord. 